Meta

Journal des tradlucteurs

Translators' Journal

\title{
Translators and Interpreters - Siblings or a Breed Apart ?
}

\section{Thérèse Nilski}

Volume 12, numéro 2, juin 1967

URI : https://id.erudit.org/iderudit/003736ar

DOI : https://doi.org/10.7202/003736ar

Aller au sommaire du numéro

Éditeur(s)

Les Presses de l'Université de Montréal

ISSN

0026-0452 (imprimé)

1492-1421 (numérique)

Découvrir la revue

Citer cet article

Nilski, T. (1967). Translators and Interpreters - Siblings or a Breed Apart?

Meta, 12(2), 45-49. https://doi.org/10.7202/003736ar d'utilisation que vous pouvez consulter en ligne.

https://apropos.erudit.org/fr/usagers/politique-dutilisation/ 


\section{TRANSLATORS AND INTERPRETERS - SIBLINGS OR A BREED APART?}

Are conference interpreters best recruited among translators? Do many translators occasionally practice some conference interpretation? Among interpreters, are there many who also go in for professional translation? And are they best trained together, or apart?

To the layman, these are Kafka-esque questions. Very few members of the North-American public in fact distinguish between translation and interpretation. Only the few more versed in international affairs are aware of the difference between translation (the written transposition of texts), and interpretation (the oral transposition of spoken messages).

Small wonder then that so many people around us blithely assume that anyone who more or less fluently converses in two languages, can translate; and anyone who translates is more or less automatically capable of interpreting.

While exercised in different contexts, translation and interpretation share a basic common goal : the conveying of information across a language barrier. Both are similarly affected by the current tempo of discovery : in common with many other professions today, neither translators nor interpreters can stop learning; their whole working lives are a continuing process of apprenticeship. Moreover, new light is being shed upon both activities through present advances in computer technology, and through our era's growing scientific knowledge of the processes of the human brain, including thinking, learning and communicating. This is the kind of research that will eventually tell us whether the process of communicating ideas and feelings in writing is significantly different from the work performed by the mind in direct inter-personal communication.

We shall then be in a better position to understand a rather curious empirical finding that has lately been gaining ground. It seems so natural to assume that translating and interpreting, which both deal with languages, are kindred occupations. And yet a consensus has been developing fairly consistently, first in Europe, then, independently, in the Americas, and now in Asia and Africa as well, that good translators do not necessarily make good interpreters - and vice versa. Few people turn out to be equally good at both jobs, or indeed equally well enjoy doing them both. This does not imply that the two occupations are fundamentally incompatible. A good translator may also happen to be a good interpreter, just as he may happen to be a good musician or painter or poet; a good interpreter may also be a good lawyer, or journalist, or actor - or translator. But the two are by no means synonymous.

Of course, economic factors enter the picture at this point, and do little to clarify it. While there is no less chronic a shortage of good translators than of good interpreters - the nature of translating is such that it attracts many talented people 
who are only willing to do this work part-time: e.g. writers, poets, broadcasters, scholars. Now, of the full-time translators who also turn out to be good interpreters and who enjoy the peculiar challenges of this job - most will tend to become fulltime interpreters, because this is at present financially more rewarding. On the other hand, a good many professional interpreters do in fact some written translating - sometimes because it is part of their job if they are permanently employed by e.g. an international organization, sometimes because they enjoy the change of pace and discipline, least often of all to supplement their income, because, if they are any good at all and unless they live in some out-of-the-way place, or have a seldomused combination of languages, there is usually more than enough work for them as conference interpreters.

But what then of the relative advantages and disadvantages of combining both occupations? How useful is it for the same person to try to be adept at both? Is switching back and forth helpful or harmful? Here again, the picture is far from clear-cut: according to circumstances, people will tend to stress either the pros or the cons. As usual, the truth probably lies somewhere in between. The absence of an established opinion is to some extent reflected by the differing practices of, say, international organizations. Some, like the United Nations, keep their translation and interpretation sections uncompromisingly apart. The translators never interpret. The interpreters never have anything to do with translation. Other organizations, like Montreal's U.N. agency, the International Civil Aviation Organization (ICAO), have a language branch which combines both the translation and interpretation sections. Those who work in the branch tend to specialize in one or the other form of activity. But while the interpreters are all expected to do written translations between the sessions of deliberative bodies, translators are seldom if ever expected to do sporadic interpretation; and if, indeed, they show any talent and taste for it, they tend to move over into the interpreter category.

Incidentally, however, the one thing that both groups have in common is their rigorous respect for the end-product of translation or interpretation: what is respectively called the «target $»$ or $《$ active $»$ language. There is no playing about with its quality : language officers have to meet the most stringent requirements regarding their ability to handle what is commonly (and often misleadingly) known as their «mother tongue ». Requirements concerning «source» or «passive » languages are also strict but not as uncompromising. Thus, bivalence, and all the more so polyvalence, are not encouraged and are in fact treated with the greatest circumspection. There is a lesson, here, of special relevance to us in Canada (as for all bilingual countries) : while general fluency in at least one, and preferably two or three languages besides one's mother tongue is a useful achievement towards which modern education should be geared for everyone (here as it is in Europe); for certain tasks and at certain levels of complexity, notably for translating and interpreting, to cultivate easy versatility in the same person may be more of a vice than a virtue.

The reason why most people have a definite bent in favour of either translation or interpretation is no doubt largely a matter of temperament and talent. Those of us with experience in either field may have a pretty good idea of the kind of person who will do well in it; but more precise research is needed, and our various professional associations might usefully encourage further study of the actual combin- 
ations of aptitudes a student should have to make a success of a career in translation, interpretation, or both. Many competent people who have done both forms of work claim that each sharpens one's wits in a different way and that they are mutually beneficial : one is a better interpreter through having done some careful linguistic analysis, through having sat down with a dictionary, through having reviewed one's habits of expression. (Incidentally, regardless of whether they are assigned any translation duties, full-time interpreters are supposed to devote some time to stocktaking of this kind - but they in fact seldom apply such counsels of perfection, unless propelled by some higher force ... in the shape of translation.) Translators, too, may no doubt derive some benefit from an occasional work-out at interpretation. The counter-argument is that interpretation tends to encourage slap-dash, superficial habits in the translator; and I have myself experienced the hesitancy, the habit of searching for an ever-better word, that so impairs interpretation after having for some time slogged at a demanding, refractory text ... The dilemma, I suppose, calls for a common-sense answer. The two activities are not mutually exclusive, but one should be careful. It is bad to be constantly chopping and changing from one to the other. There is, every time, a process of adaptation, shorter or longer according to circumstances - and one should have the sense to make an adequate allowance for this warm-up period of relative inefficiency.

If translating and interpreting in fact call for different aptitudes and for the exercise of different skills - then what about training ? Here again, opinions have varied widely. Not so much, perhaps, over the training of translators, which has an older and better-established tradition behind it, as over the training of that new breed of tight-rope artist, the interpreter. The trouble is that, until very recently, most of the renowned interpreters were accidents of nature, the children of freak circumstance, the mutants of international evolution : no one had ever given them any formal training for a form of work which somehow just happened. But more and more, in response to growing demand, «schools of interpretation $»$ have been springing up all over the world and progressing through trial and error. By now, a substantial amount of experience has begun to accumulate. Several of the schools in Europe are producing a new crop of brilliant young interpreters, who do not have to go it alone, but emerge into this changing world armed with all their elders' tricks-in-trade. Much of the credit for this goes to AIIC (pronounced « Ayeeeck $\gg$ !, as interpreters familiarly call their powerful international arm, the prestigious, Paris-based, world-wide « Association Internationale des Interprètes de Conférence »). AIIC has provided a forum through which interpreters have, over the years, worked out their standards, adapted their working methods to evolving requirements, developed criteria of proficiency; and is now, among other things, devoting a good deal of attention to the problem of training new interpreters and to evaluating the various systems used by existing schools.

Several months ago, an AIIC-organized symposium was held in Paris, to foster the first general exchange of experience and information on this problem. A detailed report on the symposium is expected soon, and it should be of vital interest in Canada, where the training of competent new interpreters is a matter of growing urgency. This, too, is a field where a general consensus seems to be emerging. Initially, the tendency was to require potential interpreters to go through a full translator-training program before embarking on interpreter training. It has 
turned out that this discourages or frightens away many of the most promising interpreter trainees, who are by temperament ill-suited for such a program. At present it is more and more widely accepted that interpreters are best trained independently, in relatively short, very intensive courses given to rigorously pre-selected applicants. In general, practice is showing that in order to make the grade, interpreters-to-be must have a university education in their principal or «active » language. In other words, before they start training as interpreters, they should already hold a university degree in one of the recognized disciplines - history, economics, political science, law, mathematics, science or any other field - not necessarily related to languages or linguistics. Moreover, they should already have an excellent knowledge of at least one, and preferably two additional languages not every combination of such languages being equally useful in all parts of the world. The prerequisites for a successful career in interpretation are explained in greater detail in one of AIIC's publications, la Plaquette d'orientation professionnelle, available from the Association's headquarters (33, rue des Archives, Paris, $4^{\mathrm{e}}$ ).

All this, then, naturally brings us to the next question: what is the school of interpretation supposed to teach its students, as distinct from the school of translation? Practice in the skills of listening and speaking concurrently, of course - the answer seems obvious ... and yet the results of this approach turn out to be unaccountably meager. In fact, the best European schools, the ones that turn out a high ratio of competent, practicing interpreters, have discovered that, in order to teach acceptable simultaneous interpretation - they must go back to one of the older, and gradually vanishing forms of interpretation : consecutive. It is through a progression of exercises aimed at teaching the student to grasp, analyze, remember, and only subsequently reproduce the message of a speaker, that today's best simultaneous interpreters are trained.

Paradoxical ? Not at all. As a well-known interpreter (who also teaches in one of Europe's outstanding schools) explained:

To do their kind of job, linguistic ability apart, you'll admit interpreters have to be pretty knowledgeable : nuclear physics one day, Common Market trade negotiations the next, then right bang into genetics research! - how do we prepare our students to handle all that ? Not by teaching them vocabularies - that would be grossly inadequate, liable to impardonable error, and probably out of date in no time flat. Not by teaching them the substance of subjects other than our own, either. We have no business teaching them languages, or international relations, or the quantum theory. If necessary, others can do it - far better. What interpreters-to-be must learn here, are the skills of rapid assimilation, and communication. How and where to read up, find out enough about a subject to be able to follow intelligently any formal exchange between experts in that field, in the two or more languages the student works with (his active, and his passive languages). How to express himself coherently, lucidly, in his own language. This doesn't presuppose that the interpreter will know enough about a subject to take part in the experts' discussion or to exercise his critical judgment concerning the value of the various arguments raised. It does presuppose he will be able to grasp and convey these arguments without distortion.

What are the practical kinds of exercises we give students to accomplish this? 
Well - apart from working on consecutive interpretation, which is perhaps the most useful tool at our disposal (and is only in the later stages followed by booth practice, in simultaneous) - say we assign them a 3-hour period in which to assimilate the contents of a «Que sais-je?» (a French series of excellent pocket-books on a wide range of specialized topics). The student must then deliver a talk on the subject, explaining it to the rest of his class, and coping with a question-and-answer period. Or again, each student is in turn given a week-long assignment, leading to a half-hour lecture he must give his classmates on e.g. recent developments in laser technology; or on the technological (or economic, or political) implications of the Aswan Dam project; and so on. This requires students not only to delve into libraries, but also to keep track of the current press and to interview or collect material from government departments, private corporations, or foreign embassies.

The professor chuckled at this point. \& I grant you, I get quite a lot out of such homework myself ... Only last week, one of my students gave us a splendid exposé on polymerization - since when I've been feeling like a fish in water at the present Plastics conference!»

Simple, my dear Watson! But it is precisely this ability to conjure up bits of intelligence out of thin air - to grasp and process information rapidly, almost subconsciously - that is perhaps the most distinguishing mark of the good interpreter. It is thanks to both painstaking training and experience that the interpreter can, after a bare minimum of one or two days devoted to briefing sessions before a highly specialized conference, manage to interpret expert discussions between leading endocrinologists, ecumenical theologians, or space researchers.

Indeed, confirmation of this ability came at a recent world congress on psychopharmacology in the United States - when one of Canada's most eminent multilingual psychiatrists was asked by the conference chairman to give the team of interpreters their usual briefing. «Oh, I'd be delighted, said the doctor, I've already done this a couple of times, before other psychiatric congresses; and these people are wonderful to talk to. I find they're better than medical students at understanding straight off whatever it is you're trying to tell them ... $\gg$ Further kudos for the interpreters came after the conference's grand opening meeting with its keynote address by one of the foremost luminaries in the field. One of the members of the learned audience came up to thank the interpreters. « Professor X was brilliant, he said, and I had no difficulty in following him. But I preferred to listen to you : it came over so much more clearly still. » Such tribute is perhaps the exception; and I must sadly admit it is only rarely deserved. But then, keeping up a pure pitch of perfection is doubtless beyond the reach of our human condition; and indeed, we must constantly guard against over-reaching ourselves. Traduttore, traditore has been levelled against us as much as against our sister-profession; although it may stick in the literary and artistic fields, it is far less apt to do so where our specialty : the art of communicating information - is involved. Communicating the message clearly and faithfully, across a language barrier, is what our profession is all about. This we have in common with translators. But though the words we handle may be the same, our tools and materials and methods tend to be prodigiously different, and so to require a different bent of mind, a different emphasis in training.

THÉRÈSE NILSKI 